International Journal of Advances in Chemistry (IJAC) Vol. 3, No.3/4, November 2017

\title{
ARTIFICIAL NEURAL NETWORK APPROACH TO MODELING OF POLYPROPYLENE REACTOR
}

\author{
Peter Karas and Stefan Kozak \\ Institute of Automotive Mechatronics, Faculty of Electrical Engineering and \\ Information Technology, Slovak Technical University, Bratislava, Slovakia
}

\begin{abstract}
This paper shows modeling of highly nonlinear polymerization process using the artificial neural network approach for the model predictive purposes. Polymerization occurs in a fluidized bed polypropylene reactor using Ziegler - Natta catalyst and the main objective was modeling of the reactor production rate. The data set used for an identification of the model is a real process data received from an existing polypropylene plant and the identified model is a nonlinear autoregressive neural network with the exogenous input. Performance of a trained network has been verified using the real process data and the ability of the production rate prediction is shown in the conclusion.
\end{abstract}

\section{KEYWORDS}

Identification, model predictive control, neural networks, polypropylene, fluidized bed reactor

\section{INTRODUCTION}

Intelligent control methods belongs to the control techniques that use various artificial intelligence computing approaches like fuzzy logic, machine learning, evolutionary computation, neural networks and genetic algorithms. General description could be that intelligent control achieves the control engineering via emulation of a biological intelligence [22]. For better understanding of the neural networks, imagination of a multi-dimensional input-output space is needed. Suppose this multi-dimensional space as a two input and one output space.

\subsection{Neural Networks}

\section{$\underline{\text { Definition }}$}

Artificial neural network simulates main behavioral functions of biological neurons by collection of multiple signals - inputs, the threshold switching function - activation function and adaptation of the transmission rate of inputs - adaptation of the weights of particular inputs.

In Figure 1 an artificial neuron is showed with $n$ inputs and $n$ weights to produce a single output using sigmoid characteristic - the activation function. 
International Journal of Advances in Chemistry (IJAC) Vol. 3, No.3/4, November 2017

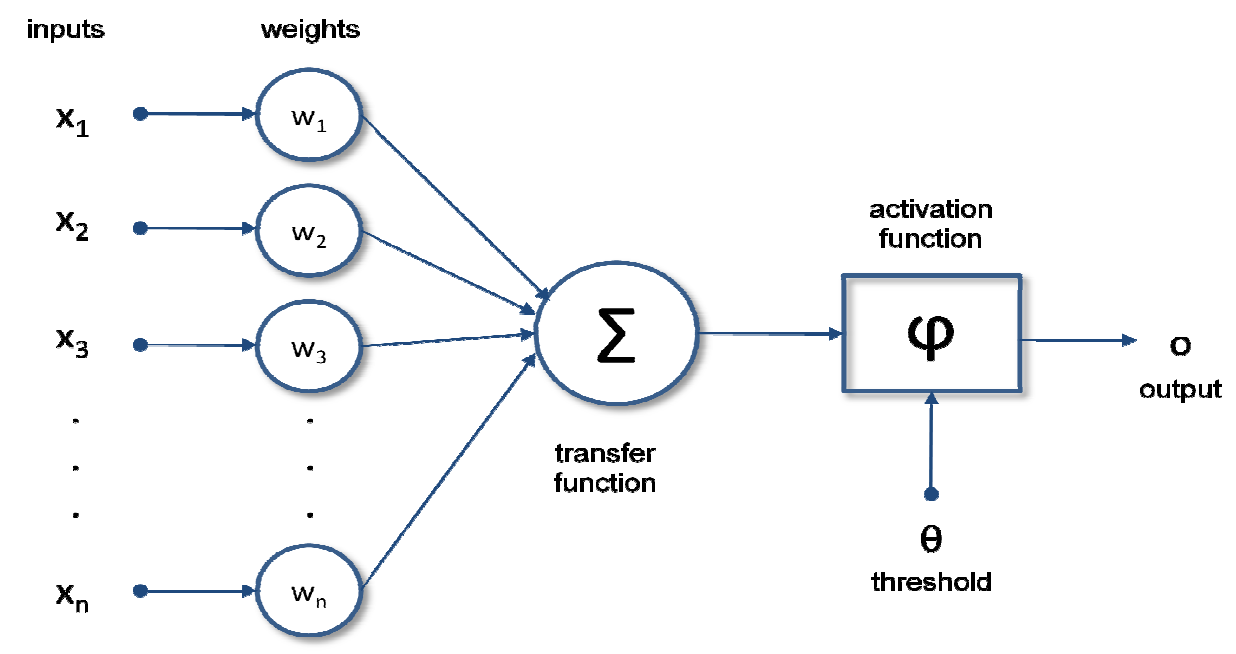

Figure 1. Block scheme of artificial neuron

Typical Neural Network (NN) structures include feed-back and feed-forward NNs. The feedback networks can have signals travelling in both directions (from input to output and from output to input) by introducing loops in the network [4]. Feed-back networks can get extremely complicated. Feed-back NNs are dynamic - their state is changing continuously until they reach an equilibrium point [3]. They remain at the equilibrium point until the input signals change and a new equilibrium needs to be found. Due to feedback there is no guarantee that the networks become stable. Feed-back networks can converge to one stable point, limit-cycle or divergent. Another type of NN is a multilayer feed-forward NN.

The basic element of a neural network is a simple computational or processing unit that is characterized by

$$
\begin{array}{ll}
\text { 1. } & \theta_{w} \in \mathbb{R}^{n_{\theta_{w}}}-\text { a vector of weights } \\
\text { 2. } & \theta_{b} \in \mathbb{R}-\text { a bias or offset } \\
\text { 3. } & s: \mathbb{R} \rightarrow \mathbb{R}-\text { an activation function }
\end{array}
$$

If $z \in \mathbb{R}^{n_{z}}$ is an input vector, fed to the processing unit, the activation function computes $s\left(\theta_{w}^{T} Z+\theta_{b}\right)$ and this value is then taken as an output of the unit. If we connect a finite number of such units in parallel into a layer and subsequently connect a finite number of such unit-layers in series only by feed forward connection we create an architecture called multilayer feed forward neural network of a multilayer perceptron (MLP), shown in Figure 2. 
International Journal of Advances in Chemistry (IJAC) Vol. 3, No.3/4, November 2(

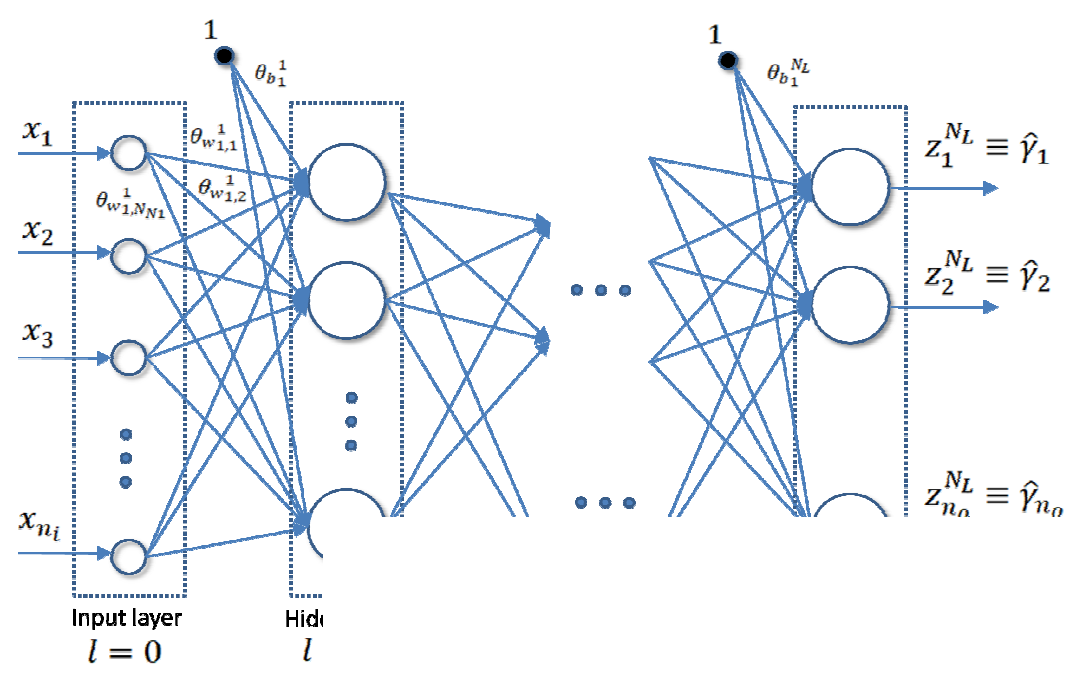

Figure 2. Block scheme of multilayer perceptron (MLP)

The $i t h$ node in the $l t h$ layer of the network compute its output $z_{i}^{1}$ according to

$$
\begin{gathered}
u_{i}^{l}=\sum_{j=1}^{N_{N_{l-1}}} \theta_{w_{i j}}^{l} z_{j}^{l-1}+\theta_{b_{i}}^{l} \\
z_{i}^{l}=s\left(u_{i}^{l}\right)
\end{gathered}
$$

where $l=1,2, \ldots, N_{L}$ is the hidden layer number, $i=1,2, \ldots, N_{N_{l}}$ is the node inde: layer, $\theta_{w_{i j}}^{l}$ is weighting factor of the connection between je $j t h$ node of the $(l-1) t$ $i t h$ node of the $l$ th layer and $\theta_{b_{i}}^{l}$ is the bias of the ith node in the lth layer. The processing function of the $i t h$ node in the $l$ th layer is denoted by $u_{i}^{l}$ and the correspc output is then denoted by $z_{i}^{l}$. The input layer, $l=0$, is a special layer because it pr the distribution of inputs $x_{i}$, for $i=1,2, \ldots, n_{i}$, among the nodes of the first hidden 1 ; It can be seen as

$$
z_{i}^{0}=x_{i}, \quad \text { for } i=1,2, \ldots, n_{i}
$$

The variable $u_{i}^{l}$ is sometimes called an activation of the node and serves as an input activation function $s(u)$. This function is usually chosen as

Or

$$
s(u)=\frac{1}{1+e^{-u}}
$$

$$
s(u)=\tanh (u)=\frac{1-e^{-2 u}}{1+e^{-2 u}}
$$

For the last hidden layer we often chose a linear processing function

$$
s(u)=u
$$


To make possible any range for the MLP outputs $z_{i}^{N_{L}}$. [49] Overall family of functions $\mathcal{F}$ that can be realized by an MLP is characterized by

1. The number of inputs and outputs $n_{i}, n_{o}$;

2. The number of layers $N_{L}$, including the output layer

3. The number of nodes in hidden layers $N_{N_{l}} l=1,2, \ldots, N_{L}-1$

4. The set of weights $\theta_{w_{i j}}^{l}$ and biases $\theta_{b_{i}}^{l}$

5. The processing function $s(u)$.

The process of iterative tuning of weights and biases is called learning.

Hebian learning algorithm increases a weight $w_{i}$ between a neuron and an input $x_{i}$, if the neuron $y$ fires.

$$
\Delta w_{i}=a y x_{i}
$$

where $a$ is learning speed. Weights are strengthened if units connected with the weights are activated. Weights are normalized to avoid an infinite increase of weight value.

Levenberg - Marquadt algorithm is the most used and most effective supervised learning algorithm for majority of tasks. It is a back-propagation algorithm which iteratively determines weights of the feed-forward NN.

Let assume that vector $\boldsymbol{E}$ is an error between the NN output $\boldsymbol{o}^{\mathbf{3}}$ and desired - supervisory output data $\boldsymbol{y}$. The superscript means a layer number, so $\boldsymbol{o}^{\mathbf{3}}$ means an output from output - final layer. The NN outputs depend on synaptic weights so the $\boldsymbol{E}$ must be a function of weights $\boldsymbol{w}$.

$$
E(\boldsymbol{w})=\frac{1}{2} \sum_{j=1}^{N_{k}}\left(\boldsymbol{o}_{j}^{3}-\boldsymbol{y}_{j}\right)^{2}
$$

The searching direction of smaller error is determined by calculating a partial differential. The searching direction is then\

$$
\boldsymbol{g}=-\frac{\partial E(\boldsymbol{w})}{\partial \boldsymbol{w}}
$$

Weight update rule of LMA is then determined by

$$
\boldsymbol{w}_{k+1}=\boldsymbol{w}_{k}-\left(\boldsymbol{J}_{k}^{T} \boldsymbol{J}_{k}+\boldsymbol{\mu} \boldsymbol{I}\right)^{-1} \boldsymbol{J}_{k} \boldsymbol{e}_{k}
$$

where $\left(\boldsymbol{J}_{k}^{T} \boldsymbol{J}_{k}+\boldsymbol{\mu} \boldsymbol{I}\right)$ is the Hessian matrix in $k$-th step. In order to make sure that the Hessian matrix is always invertible Levenberg-Marquadt added combination coefficient $\boldsymbol{\mu}$. When combination factor $\boldsymbol{\mu}$ is small (almost zero), the equation will result into

$$
\boldsymbol{w}_{k+1}=\boldsymbol{w}_{k}-\left(\boldsymbol{J}_{k}^{T} \boldsymbol{J}_{k}\right)^{-1} \boldsymbol{J}_{k} \boldsymbol{e}_{k}
$$

where Gauss - Newton algorithm will be used. On the other hand, when the combination factor is too large the equation will result into 


$$
\boldsymbol{w}_{k+1}=\boldsymbol{w}_{k}-\alpha \boldsymbol{g}_{k}
$$

where the Steepest Descent Algorithm will be used.

Since the calculation is conducted in direction from the output layer to input layer, this algorithm is named the back-propagation algorithm. When a sigmoid function is used for the activation function of neurons,

the differential is determined as,

$$
f(x)=\frac{1}{1+e^{-x+T}}
$$

$$
\frac{\partial f(x)}{\partial x}=(1-f(x)) f(x)
$$

and the calculation of the algorithm becomes simple.

\section{NONLINEAR Process IDENTIFICATION}

Many studies have been reported focusing on the petrochemical industry, especially the polymerization process. The polymer materials are widely used in many different areas. Due to the high and differentiated market demand of polymers, the polymerization process is continuously in development. Polypropylene is normally though and flexible, especially when copolymerized with ethylene. Perfectly isotactic polypropylene has a melting point in the range from $160^{\circ} \mathrm{C}$ to $166^{\circ} \mathrm{C}$. The Melt Flow Rate (MFR) or Melt Flow Index (MFI) is a measure of molecular weight of polypropylene. The measure helps to determine how easily the molten raw material will flow through the processing. As the MFI increases, some physical properties like strength will decrease. MFI and MFR polymer properties depend on the polymer production process and the level of control. One of the key properties to observe and control is a production rate. There are three general types of polypropylene:

- homo-polymer

- random copolymer

- block copolymer

The copolymer is usually used with ethylene. Ethylene-propylene rubber (EPDM) added to polypropylene homo-polymer increases its low temperature impact strength. Randomly polymerized ethylene monomer added to the polypropylene homo-polymer decreases the polymer crystalinity, lowers the Melting point and makes the polymer more transparent. Traditionally, three manufacturing processes are the most common ways to produce polypropylene.

1. Hydrocarbon slurry or suspension

2. Bulk (or bulk slurry)

3. Gas phase

Because of the high efficiency and complexity of the process, the gas phase production type is the most used in petrochemical plants [11]. Gas phase production process uses gaseous propylene in contact with the solid catalyst, resulting in a fluidized-bed medium. Due to nonlinearity in the process dynamics and difficulties involved in the control of the gas phase propylene polymerization fluidized bed reactor, an efficient process control scheme is vital for stable and efficient operation of the process. Linear MPC algorithms are unable to handle the 
complexity of such non-linear process. The non-linear MPC has good capability to improve control and operation of the non-linear processes such as this polymerization process. Successful applications of Non-linear Model Predictive Control (NMPC) with capability of dealing with unanticipated changes in process dynamics through the state estimator, on polymerization reactors have been reported. Summary of relevant studies in olefin polymerization and its control are listed and well summarized by [40]. Mostly implemented polypropylene technology is UNIPOL. The Figure 3 shows an example of olefin polymerization process - industrial gas phase fluidized-bed polypropylene (UNIPOL-type) reaction process. Main functional parts of UNIPOL polypropylene reactor are

- Reactor - fluidized bed gas phase polymerization reaction system

- Cycle gas compressor - continuous flow of cycle gas

- Cycle gas cooler - removes reaction heat

UNIPOL Polypropylene Technology is a simple and delicate processing system, comprising of one or two gas phase fluidized-bed reactors. To produce homo-polymers and random copolymers a single reactor is used. In this work a single reactor is considered for homo-polymerization. The reactor is a gas phase reaction system using Ziegler - Natta catalyst. Simplified block diagram is shown in Figure 4. The cycle gas supplies fresh propylene and fluidizes the reactor bed.

Monomer (propylene), hydrogen, nitrogen and occasionally ethylene is provided by the gas stream to reactor. The cycle gas feed stream fluidizes and agitates at the same time as the reactor bed and removes heat generated by polymerization reaction.

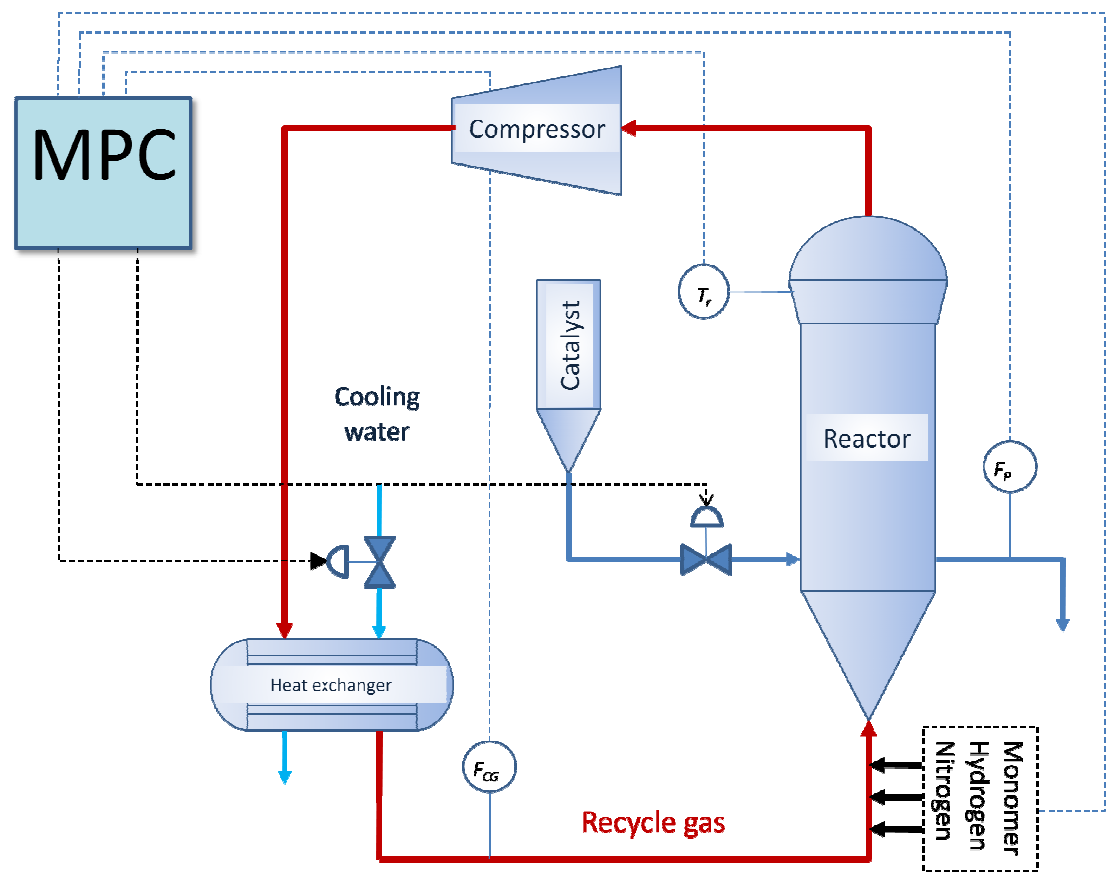

Figure 3. Simplified schematic of an industrial gas-phase fluidized bed polypropylene reactor with model predictive control design

Polymerization occurs in the pores of Ziegler - Natta catalyst and presence of co-catalyst and donor (selectivity control agent). The not reacted gas exits the top of the reactor and is then compressed and cooled before being fed back into the bottom of the fluidized bed. 
The polymer production rate in this system also depends on the heat removal from the cycle gas since the polymerization reaction is exothermic. To achieve a stable polymer production rate, which is an important goal for this industry, it is necessary to keep the bed temperature above the dew point of the reactants to avoid the gas condensation and bellow the melting point of the polymer to prevent particle melting, agglomeration and resulting reactor shutdown. Polypropylene process stabilization is a challenging problem and an important task for the design of the control system of the process.

\section{Case STUdy}

Subjected polymerization reaction takes place in a fluidized-bed reactor and basic overview is shown in Figure 4. Prepared catalyst and purified reactants (propylene, hydrogen, and occasionally ethylene) are fed continuously to the reactor. Liquid Teal (tri-ethylaluminium) and either donor (SCA - Selectivity Control Agent) are fed to the reactor inlet gas stream as cocatalysts. An externally cooled cycle gas loop fluidizes the reactor bed, provides fresh reactants, and removes heat from the exothermic polymerization reaction. The product flows intermittently from the reactor through two Product Discharge Systems (PDS), which operate in a sequentially alternating mode. The resin is transported to a receiving vessel by a dense phase conveying system. The reaction system consists of a reactor, a cycle gas cooler and a cycle gas compressor. Gaseous reactants (a mixture of propylene, hydrogen, and occasionally ethylene) and inert gases are continuously recycled by the cycle gas compressor through the reactor bed with fluidized resin containing the catalyst. The heat of polymerization is transferred to the cycle gas and released in the external water-cooled cycle gas cooler.

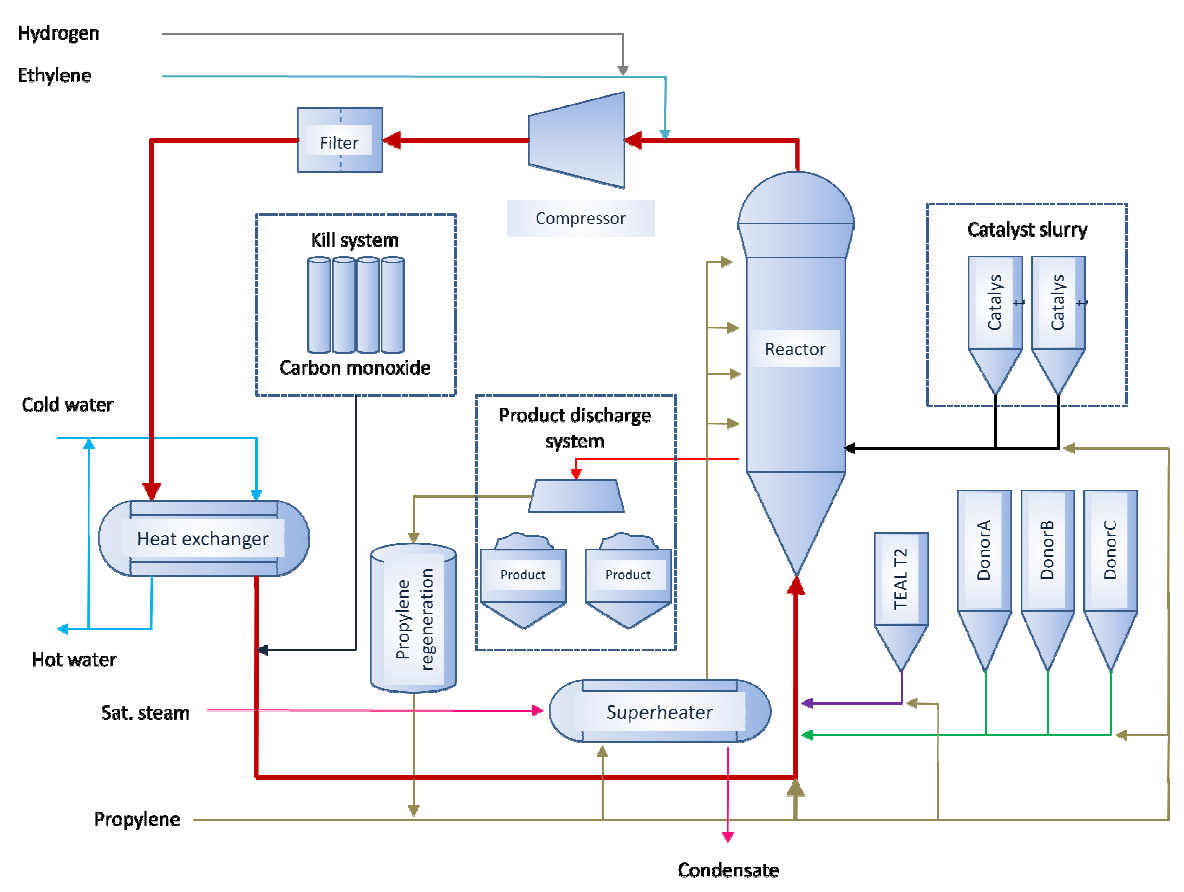

Figure 4. Principal diagram of the main process part of polypropylene reactor

The reactor is a skirt supported cylindrical vessel with a top expanded section for solids disengagement. A perforated distributor plate supports the bed of granular resin and distributes the gas flow into the bottom of the bed. The cycle gas compressor is a single stage, constant speed, centrifugal compressor. The cycle gas circulation flow rate is controlled by discharge throttling and shovel angle of rectifier section of the compressor. The cycle gas cooler is a single- 
pass shell and tube heat exchanger. The cycle gas flows through the tubes and the cooling water flows counter-currently through the shell. The temperature is controlled by varying the cooling water makeup/return rate.

Several simplifications have been considered during the analysis and design:

1. Propylene or Nitrogen used for purging and conveying of catalyst/co-catalyst considered as negligible compared to the fresh propylene monomer feed.

2. Single feed of already prepared catalyst slurry (catalyst mixed with mineral oil) considered instead of two standalone, stirred vessels with catalyst and mineral oil feeding systems. These two systems are never used both at the same time.

3. Shell - tube cycle gas cooler make-up/fresh cooling water input system simplified to shell - tube exchanger with cooling water input and output with real flow and temperature values. Only temperature and flow of water considered in this work.

4. Product discharge systems switching are not included because these are not related directly to the polymerization reaction process. Production rate data are downloaded from the control system used as output variable.

Detailed study and analysis of UNIPOL process and technology units were necessary to understand the polypropylene production unit. Several legal steps were required for the proper protection of private property and author rights of license owner and technology operator. Consultancy with people responsible for the polypropylene process operation and maintenance was necessary for understanding of the process control and the operation. Polypropylene production unit is a complex plant consisting of different standalone units. Focusing only on polymerization reaction control, deep technology breakdown was required for the recognition of the process parts/units importance. Several partial tasks recognized during solution development and model identification:

1. Analysis of recorded data and measured values

2. Reactor model

3. Comparison of data measured vs. data simulated

Partial tasks, like catalyst vessels level, concentration and mixing control, are solved by lowerlevel distributed control system (DCS). Because it is physically impossible to measure real amount of product on-line, mathematical model is used for the product production rate estimation. Model details are unknown and licensed by provider of technology. The main parts of the technology were chosen considering the priority and effect to the control of polypropylene reaction. The accuracy of different measurement instruments was recognized as important factor during analysis of downloaded data. As an example we can take a simple orifice flow meter which is used to measure the cycle gas flow. This flow meter measures the flow with the accuracy of approximately $+/-5 \%$ at nominal value of approximately $30000 \mathrm{~m}^{3} / \mathrm{h}$ approximately.

\subsection{Reactor model}

The neural network training appears unsuccessful using the complete set of data and standard training methods (the neural network toolbox in the Matlab using Levenberg - Marquardt training method). However, separating the data into different sets according to product type and using of combination of two training methods - scaled conjugate gradient and Levenberg Marquardt, brings better results. The production unit is switching the production between 13 different product types - polymers, sometimes on daily basis. Production rate prediction and control is one of the key performance indicators during the plant operation and provides set points to other control loops. 


\section{CONCLUSION}

In this work we focused mainly on a design and training of a reliable model for the prediction of the reactor production rate. This value is non-linear and difficult to measure on-line as the product is removed from the reactor not periodically and depending on many variables.

Using the classic control methods often resulted into non-optimal set up of regulators and control system to achieve acceptable efficiency of the plant respecting the technology design limits. This approach frequently results into highly operator dependant control. In many cases, including the polypropylene unit described above, there are several constants which are adjusted by skilled operators to reach requested production target. Current high level control system is frequently switched off due to new procedures which are not included in current high level control system.

Identified model is a Non-linear Autoregressive neural network with Exogenous Input (NARX) where $x(t)$ represents vector of input variables which can be obtained from the field sensors and valves and $y(t)$ represents output value - reactor production rate.

$$
y(t)=f(x(t-1), x(t-2), y(t-1))
$$

NARX neural network model uses sigmoid activation function in the hidden layer and linear activation function in the output layer. Hidden layer of network has 30 neurons trained on process data. Performance of the model was evaluated using Mean Square Error method

$$
\sigma_{M S E}=\frac{1}{n} \sum_{i=1}^{n}\left(y_{i}-\hat{y}_{i}\right)^{2}=0,0143
$$

,for $i=1,2, \ldots, 58000$

and results are shown in Figure 5-13.

The results show that the identification of such a non-linear process like polypropylene reaction using real process data is possible using neural networks.

A system of reactor constraints needs further discussion with plant operations to achieve safe and reliable operation with maximum leverage of input materials and energy. The cycle gas flow variable and high/low pressure hydrogen flow signal we considered as main challenge for the identified neural network model because of high non-linearity. An appropriate filtration of measured data is necessary to achieve desirable results during the model identification. 
International Journal of Advances in Chemistry (IJAC) Vol. 3, No.3/4, November 2017

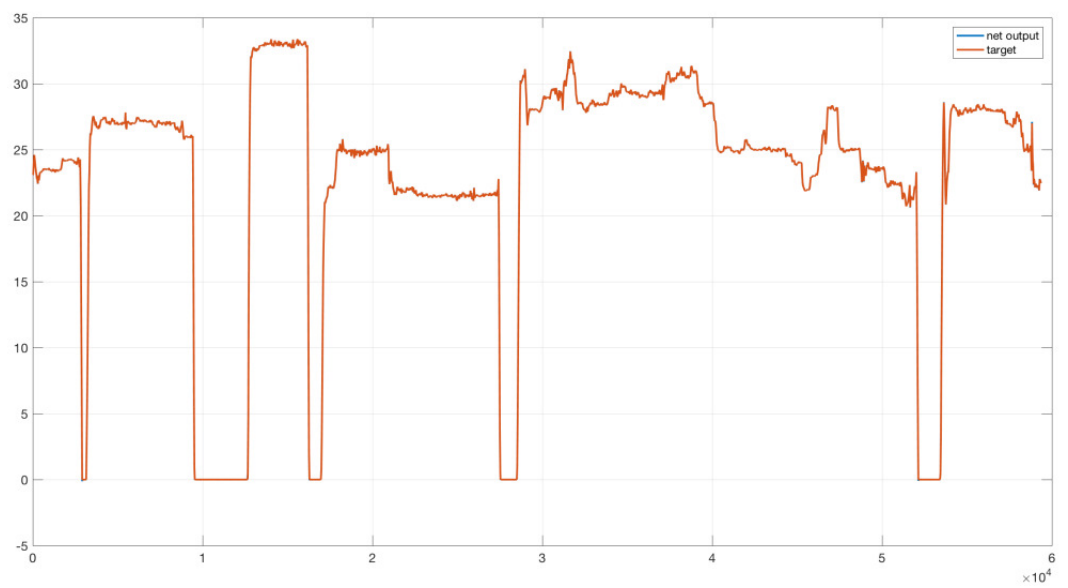

Figure 5. Time response of output variable obtained from open loop simulation

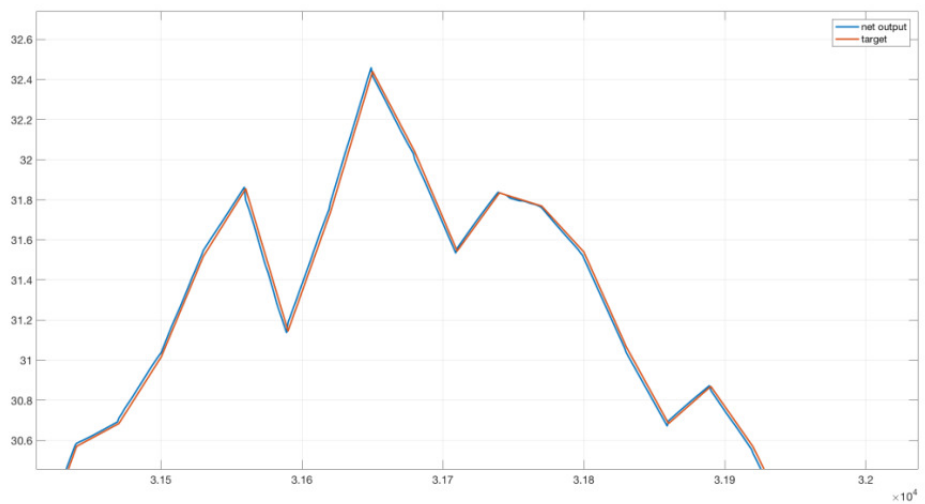

Figure 6. Time response of output variable obtained from open loop simulation - detail view

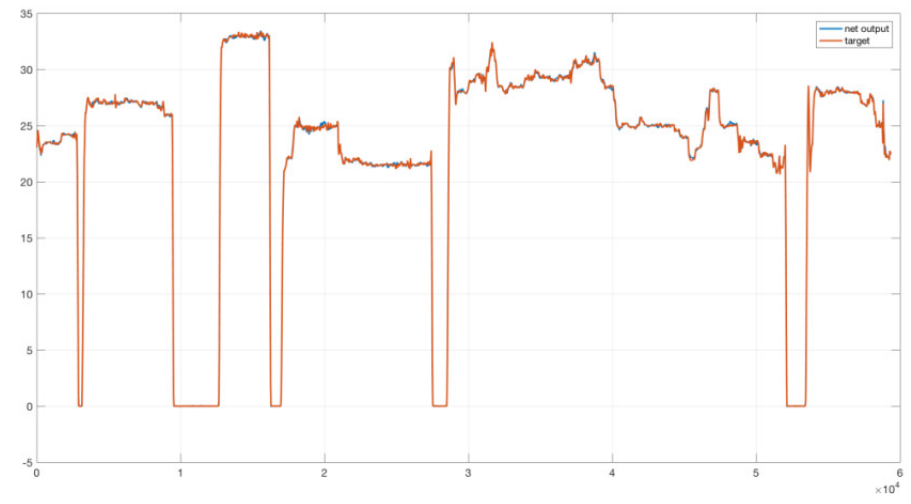

Figure 7. Time response of output variable obtained from closed loop simulation 
International Journal of Advances in Chemistry (IJAC) Vol. 3, No.3/4, November 2017

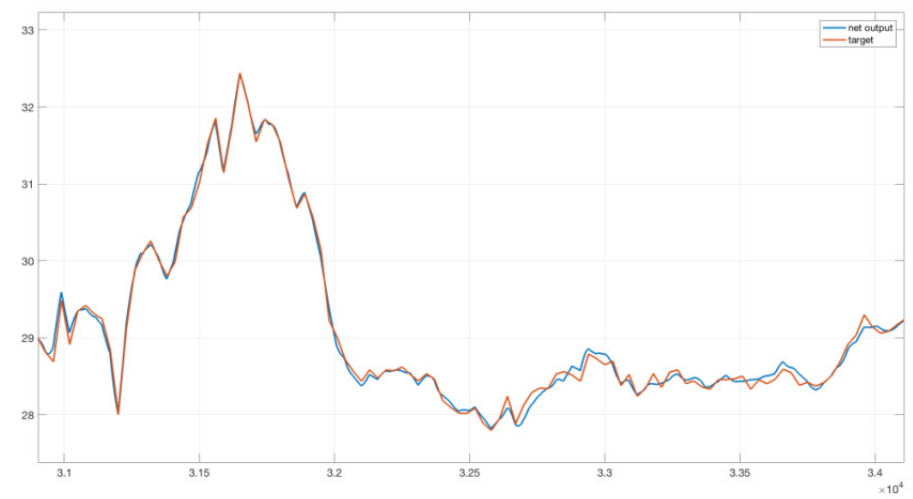

Figure 8. Time response of output variable obtained from closed loop simulation - detail view

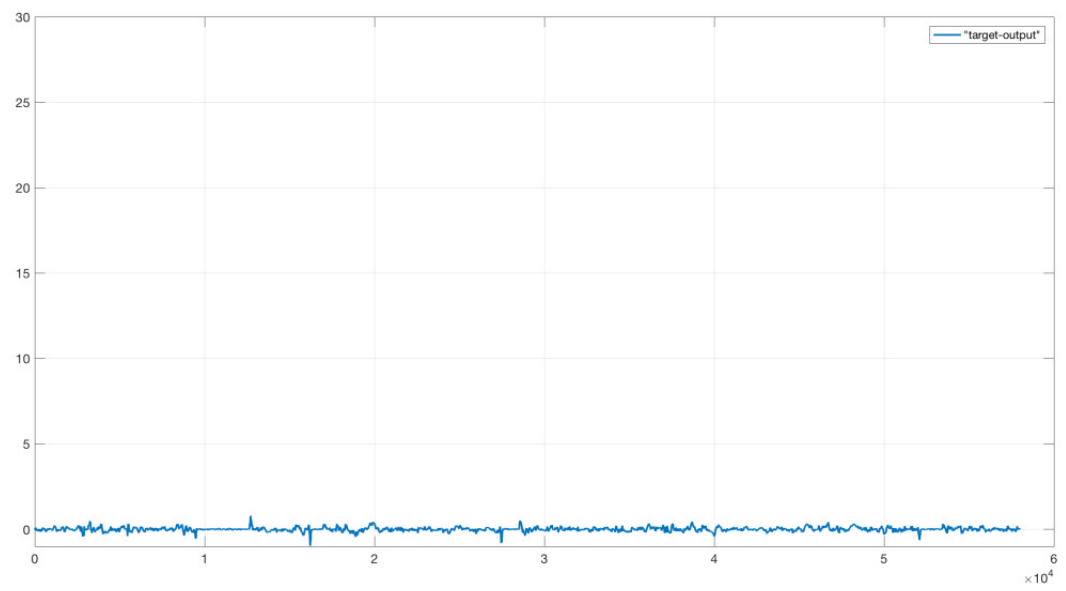

Figure 9. Time response of difference between output variable obtained from closed loop output and target values obtained from process

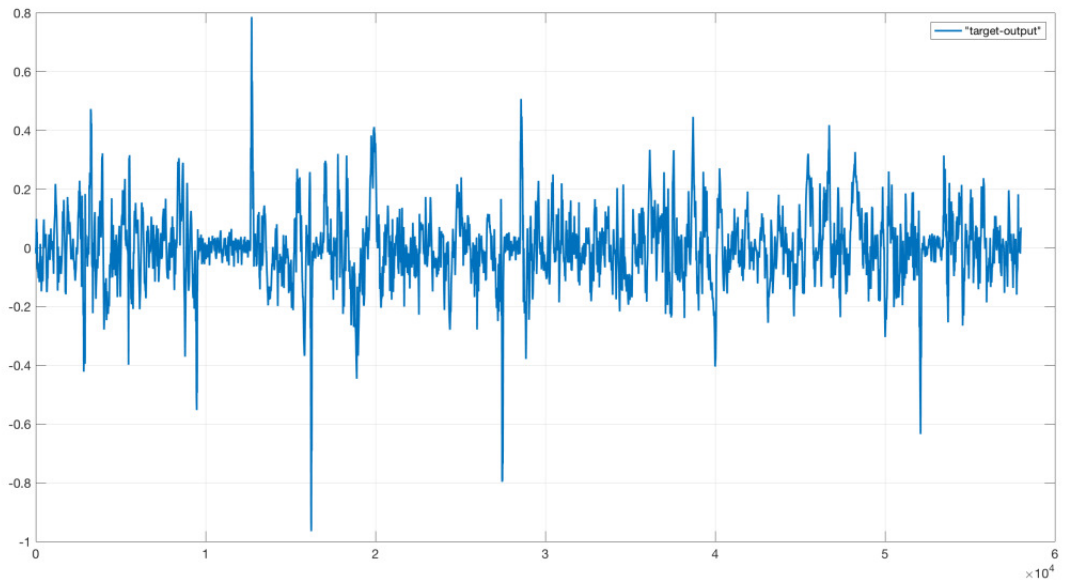

Figure 10. Time response of difference between output variable obtained from closed loop output and target values obtained from process - detail view 
International Journal of Advances in Chemistry (IJAC) Vol. 3, No.3/4, November 2017

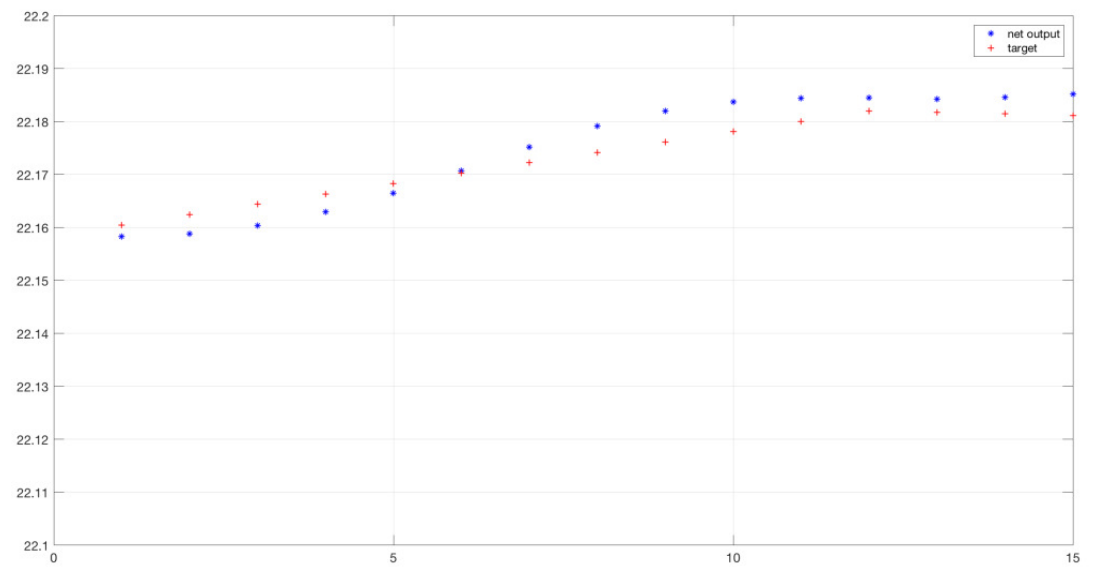

Figure 11. Time response of output variable obtained from closed loop simulation - prediction of 15 steps compared to real values (starting at step 9000)

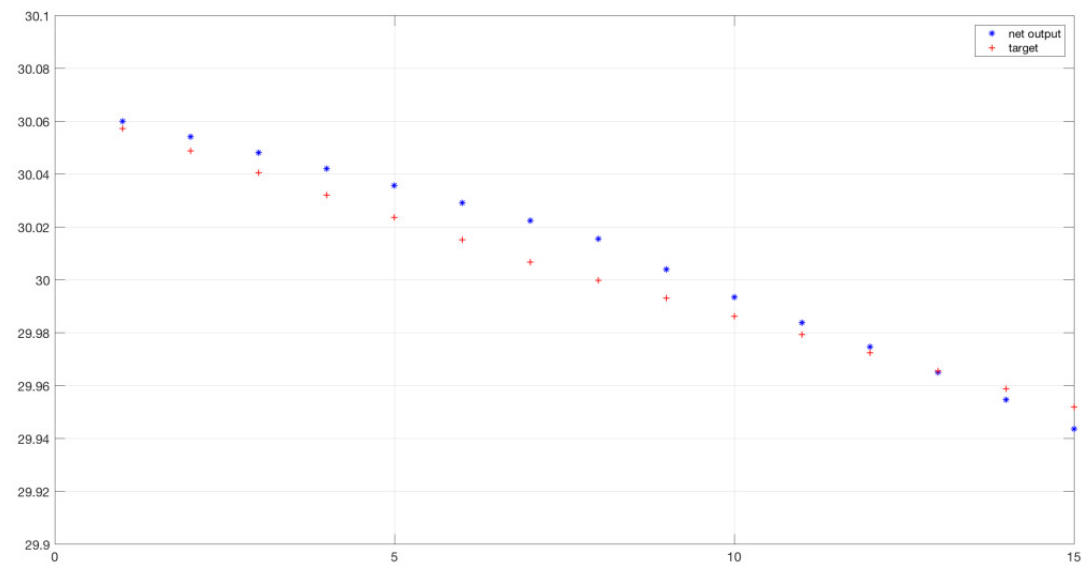

Figure 12. Time response of output variable obtained from closed loop simulation - prediction of 15 steps compared to real values (starting at 28000)

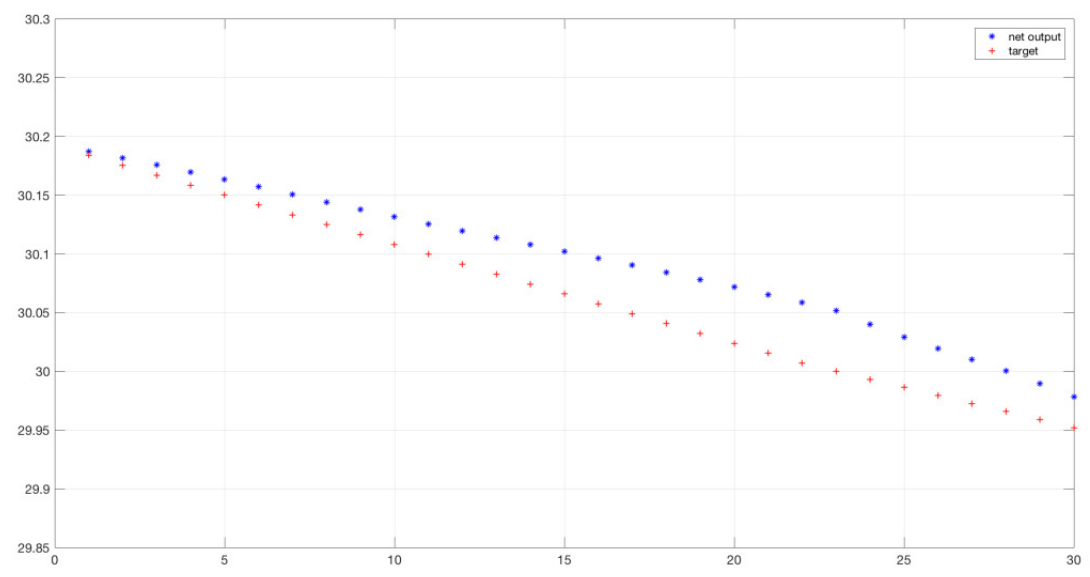

Figure 13. Time response of output variable obtained from closed loop simulation - prediction of 30 steps compared to real values (starting at 37000) 
International Journal of Advances in Chemistry (IJAC) Vol. 3, No.3/4, November 2017

\section{ACKNOWLEDGMENT}

This paper was supported by the Slovak Research and Development Agency under the project

VEGA 1/0819/17 and KEGA 030STU-4/2017.

\section{REFERENCES}

[1] SHAMIRI et al. "Kinetic modeling of propylene homo polymerization in gas-phase fluidized-bed reactor", Chemical Engineering Journal 161, 2010, pp. 240-249

[2] K. M. PASSINO, Intelligent Control : An Overview of Techniques, 2015

[3] A. ZILOUCHIAN, M. JAMSHIDI Intelligent Control Systems using soft computing methodologies, 2001,pp.41-63

[4] B. SMITH, Classical vs. Intelligent Control, EN9940 Special Topics in Robotics, 9645953 , 2002

[5] H.TAKAGI, Introduction to Fuzzy Systems, Intelligent systems : Fuzzy logic, Neural Networks and Genetic Algorithms, 1997, Ch1, pp.1-33

[6] H. YU, B.M. WILAMOWSKI, Industrial Electronics Handbook, "Levenberg - Marquadt Training", 2011

[7] H. TAKAGI, I. HAYASHI, NN-driven Fuzzy reasoning, 1991

[8] H. ICHIHASHI, T. WATANABE, Learning control by fuzzy models using a simplified fuzzy reasoning, 1990

[9] KARR et al., Improved Fuzzy Process Control of Spacecraft Autonomous Rendezvous Using a Genetic Algorithm , 1989

[10] TAKAGI et al., Neural networks designed on Approximate Reasoning Architecture, IEEE Transactions on neural networks, Vol.3, No.5, 1992

[11] RUCHIKA, NEHA RAGHU, Model Predictive Control: History and Development, International Journal of Engineering Trends and Technology, Vol.4, No.6, 2013

[12] D.Q.MAYNE, J.B.RAWLINGS, C.V.RAO, P.O.M.SCOCAERT, Constrained model predictive control : Stability and optimality, Automatica Vol.36, 2000, pp. 789-814

[13] J.MIKLES, M.FIKAR, Modelovanie, identifikácia a riadenie procesov I, Ed.1, 2004

[14] J.MIKLES, M.FIKAR, Modelovanie, identifikácia a riadenie procesov II, Ed. 1, 2004

[15] J.PAULUSOVA, M.DUBRAVSKA, Hybrid predictive controller, 2010

[16] M.LAZAR, W.P.M.H. HEEMELS, A. BEMPORAD, S. WEILAND, Discrete-time Non-smooth Nonlinear MPC: Stability and Robustness, 2007

[17] G.C.GOODWIN, M.M.SERON, J.A. DE DONA, Constrained control and estimation : An optimization approach, 2005

[18] M.BOUMEHRAZ, K.BENMAHAMMED, Constrained Non-linear Model Based Predictive Control using Genetic Algorithms, 2005

[19] J.CAUSA, G.KARER, A.NUNEZ, D.SAEZ, I.SKRJANC, B. ZUPANCIC, Hybrid fuzzy predictive control based on genetic algorithms for the temperature control of a batch reactor, Computers and Chemical Engineering, Vol.32, 2008, pp. 3254-3263

[20] J.A. ROUBOS, S.MOLLOV, R.BABUSKA, H.B.VERBRUGGEN, Fuzzy model based predictive control using Takagi-Sugeno models, 1999

[21] S.MOLLOV, R.BABUSKA, J. ABONYI, H.B.VERBRUGGEN, Effective Optimization for fuzzy Model Predictive Control, IEEE Transactions on fuzzy systems, Vol.12, No.5, 2004

[22] F.OTERO, Use of neural networks in process engineering - Thermodynamics, diffusion, process control and simulation applications, CT\&F - Cienca, Technologia y Futuro, Vol.1, No.4, 1998

[23] R.HEDJAR, Adaptive Neural Network Model Predictive Control, 2012

[24] S.PICHE, J.KEELER, G.MARTIN, G.BOE, D.JOHNSON, M.GERULES, Neural Network Based Model Predictive Control, 2000

[25] S.J. QIN, T.A. BADGWELL, A survey of industrial model predictive control technology, Control Engineering Practice Vol.11, 2002, pp.733-764

[26] V.A.AKPAN, R.A.O.OSAKWE, Multivariable NNARMAX Model Identification of an AS-WWTP using ARLS, American Journal of Intelligent Systems, Vol.4, 2014, pp.43-72

[27] A. BEMPORAD, M.MORARI, Control of Systems Integrating Logic, Dynamics, and Constraints, IFA Tech. Report AUT-98-04, 1998

[28] M.L.TYLER, M.MORARI, Propositional logic in control and monitoring problems, 1996 
International Journal of Advances in Chemistry (IJAC) Vol. 3, No.3/4, November 2017

[29] G.-Y. ZHU, M.A. HENSON, B.A.OGUNNAIKE, A hybrid model predictive control strategy for nonlinear plant-wide control, Journal of Process Control, Vol.10, 2000, pp.449-458

[30] N.N.NANDOLA, D.E.RIVERA, An improved formulation of hybrid model predictive control with application to production inventory system, IEEE Transactions on Control Systems Technology, 1063-6536, 2011

[31] J.ROMERA, C.OCAMPO-MARTINEZ, V.PUIG, J.QUEVEDO, Flooding management using hybrid model predictive control : application to the Spanish Ebro River, 2012

[32] www.mathworks.com, MATLAB® and Simulink®,1994-2015 Mathworks, Inc.

[33] M. ANKLAUFF, A.BEMPORAD, S.CHAKRABORTY, P.KUTTER D.MIGNONE, M.MORARI, A.PIERANTONIO, L.THIELE, From ease in programming to easy maintenance : extending DSL usability with montages, 1999

[34] D.MIGNONE, Control and Estimation of Hybrid Systems with Mathematical Optimization, Diss. ETH No. 14520, 2002

[35] J.LOFBERG, YALMIP : A free MATLAB Toolbox for rapid prototyping of optimization problems, 2004

[36] P.J.ANSAKLIS, Theory and Application A Brief Introduction to the Theory and Applications of Hybrid systems, Proceeding of the IEEE, Vol. 88, No.7, 2000

[37] S.KOWALEWSKI, Introduction to the Analysis and Verification of Hybrid Systems, 2002

[38] B.DE SCHUTTER, W.P.M.H.HEEMELS, J.LUNZE, C.PRIEUR, Survey of modeling, analysis, and control of hybrid systems, Technical report 09-007, 2009

[39] Y.WANG, S.BOYD, Fast Model Predictive Control Using Online Optimization, IEEE Transactions on Control systems Technology, Vol. 18, No.2, 2010

[40] A.SHAMIRI, M.A.HUSSAIN, F.S.MJALLI, N.MOSTOUFI, S.HAJIMOLANA, Dynamics and Predictive Control of Gas Phase Propylene Polymerization in Fluidized Bed Reactors, Process Systems Engineering and Process Safety, Chemical Journal of Chemical Engineering, Vol. 21, 2013, pp. 1015-1029

[41] A.SHAMIRI, M.A.HUSSAIN, A.ARAMI-NIYA, Temperature Control of Industrial Gas Phase Propylene Polymerization in Fluidized Bed Reactors Using Model Predictive Control, 3rd International Conference on Chemical, Biological and Environmental Engineering, IPCBEE, Vol. 20, 2011

[42] A.S.IBREHEM, M.A.HUSSAIN, N.M.GHASEM, Mathematical Model and Advanced Control for Gas-phase Olefin Polymerization in Fluidized-bed Catalytic Reactors, 2008

[43] M.R.SARMASTI EMAMI, Fuzzy Logic Application in Chemical Processes, The Journal of Mathematics and Computer Science, Vol. 1, No. 4, 2010

[44] EMAD ALI, Heuristic On-Line Tuning for Non-linear Model Predictive Controllers Using Fuzzy Logic, Journal of Process Control , J3(5), 2003, pp. 383-396

[45] A.S.IBREHEM, M.A.HUSSAIN, N.M.GHASEM, Advanced Control of a Fluidized Bed Using a Model-predictive Controller, Australian Journal of Basic and Applied Sciences, 3(4), 2009, pp. 3954-3974

[46] F.D.TORRISU, A.BEMPORAD, N.M.GHASEM, HYSDEL - A Tool for Generating Computational Hybrid Models for Analysis and Synthesis Problems, IEEE Transaction on Control Systems Technology, Vol.12, No.2, 2004

[47] J.H.KIM, U.Y.HUH, Fuzzy Model Based Predictive Control, IEEE 0-7803-4863-X/98, 1998

[48] Š. KOZÁK, S. KAJAN, J. CIGÁNEK, V. FERENCEY, I. BÉLAI, Advanced Information System for safety-critical processes, 2010

[49] J. MAZÁK, Transition Control Based on Grey, Neural States, 1996 